DOI: $10.34185 / 1991-7848.2021 .01 .06$

УДК 39.311-06-05

М.Г. Маліч ${ }^{6}$

\title{
МОДЕЛЮВАННЯ ПРОЦЕСУ ДЕЗІНТЕГРАЦІЇ РУДНОЇ ПОРОДИ В БАРАБАННОМУ МЛИНІ 3 ВИКОРИСТАННЯМ МЕТОДУ СКІНЧЕНИХ ЕЛЕМЕНТІВ
}

Анотація. Розглянуто особливості руху рудних матеріалів в барабанному млині. Розроблено математичну модель процесу подрібнення рудних матеріалів з позиції балансу енергетичних величин процесу руйнування За використанням методу скінчених елементів показано, що виділений в будь-якому місці елемент завантаження піддається деформації з боку сусідніх елементів завантаження (шматків руди) в умовах всебічного нерівнокомпонентного стиснення контактними силами. Проаналізовано вплив напрямку сил контактного тертя при стисненні на ефективність руйнування рудної маси Данні сили суттєво впливають на появу максимальних зсувних (дотичних) напружень, які залежать від максимальних нормальних напружень, що виникають в шматках рудної породи Показана можливість керування режимами навантаження для підвищення ефективності процесу подрібнення.

Ключові слова: рудна маса, трубний кульовий млин, контактне тертя подрібнення, руйнування, напруження, моделювання.

\section{Вступ}

Дезінтеграція шихтових матеріалів для подальшого вилучення рудної сировини є складний та енергоємний процес. Від багатьох факторів цього процесу залежить якість подрібнення та рентабельність всього виробництва в цілому. Тому пошук шляхів підвищення ефективності процесу дезінтеграції в барабанних млинах $\epsilon$ актуальною задачею. Математичне моделювання в сукупності з застосуванням сучасних комп'ютерних технологій та інженерного аналізу, які базуються на чисельному рішенні рівнянь фізики процесу 3 використанням методу скінчених елементів дає можливість на основі геометричних параметрів деформування, властивостей контактуючих матеріалів та умов роботи трубчастого млина побудувати математичну модель процеса подрібнення з високим ступенем адекватності.

\section{Постановка проблеми}

Останні публікації з дезінтеграції руд [1, 2, 3] в барабанних млинах довели що рух рудного матеріалу завантаження (рис.1) складається 3 трьох етапів: підйом по круговій траєкторії DA, падіння по параболічній траєкторії AB i

(C) Маліч М.Г., 2021 
відкат по контуру п'яти DC. При цьому існують характерні області переходу 3 однієї траекторії на іншу. Тому розглянимо поперечний переріз барабану.

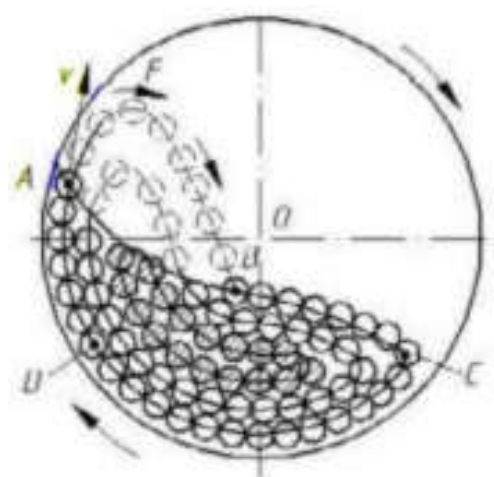

Рисунок 1 - Схема руху кульок та рудного матеріалу в трубчастому млині

Модель будемо робити по традиційній концепції - розбиття всього об’єму млина на елементи завантаження камери, які рухаються під силою тяжіння від маси шматків породи та кульок завантаження, відцентрових сил інерції та реакції поверхні обмеження простору. Однак, раніше створені моделі не в повному обсязі враховували сили внутрішнього та зовнішнього тертя між шарами матеріалу, від взаємодії шматків породи між собою, між шматком та кулькою при вологому та сухому подрібненню 3 неповною завантаженістю барабана $[4,5]$. В запропонованій моделі основну увагу приділемо силам тертя, між шарами матеріалу та силам взаємодії між матеріалом та кульками в вище згаданих умовах.

Внутрішню ємність барабанного млина із завантаженням породи та кульками розбиваємо на плоскі шари поперечним перерізом які, в свою чергу, складаються 3 шарів елементарних елементів завантаженого матеріалу та кульок, що рухаються по вище згаданих траєкторіях. Вважаємо, що зазначені елементи завантаження, на які розбитий весь обсяг млина, мають однакову форму з одиничним ребром так як було запропоновано у роботі [6].

Руйнування частинок твердого тіла відбувається в тому випадку, якщо підведеної енергії досить для подолання сил внутрішнього опору матеріалу частинки. В той же час сукупні величини різних видів деформацій та міцностей для цих деформацій, при інших рівних умовах, будуть визначати складний напружено-деформований стан частинки гірської породи, що характеризується взаємодією кожного шматка породи з іншими шматками та кульками, а також з футеровкою млина

Для інженерних розрахунків використовуються, так звані, критерії руйнування (або криві «поздовжня деформація -поздовжнє напруження та їх позамежні частини»), за якими і визначається момент руйнування частинок породи в процесі дезінтеграції. Для цього потрібно дослідити характеристики 
міцності матеріалу, внутрішнього та контактного тертя, модуль пружності та межу міцності. Ці дані отримують експериментально в умовах сучасних механічних лабораторій шляхом дослідження руйнування зразків гірських порід при різних видах деформування. Останніми роками розроблені методики аналітичної побудови кривих «поздовжня деформація поздовжнє напруження 3 їх позамежними частинами» при одновісному стисканню зразків гірських порід для різних форм руйнування, 3 достатньо високо достовірністю [7].

Треба також враховувати, що мінералогічні різновиди руд різних родовищ мають відносно великі розбіжності фізико-механічних властивостей в порівнянні з лабораторними даними [3], та ще й з урахуванням масштабного фактору та тріщинуватості, що виникає в результаті проведення буропідривних робіт в процесі видобутку корисних копалин.

Аналіз результатів досліджень показав, що міцність гірської породи на стиск в 5-10 разів вище межі міцності на зсув і в 8-15 разів вище межі міцності на розтягування. Також відомо, що зі зменшенням розміру зразків від 100 мм до 1 мм міцність при одноосьовому стисканні міцних рудовмістних порід збільшується приблизно в 3-8 разів. Авторами [5], наприклад, встановлено, що енергоємність при руйнуванні стандартних зразків магнетитових руд на ПАТ «Північний ГЗК» при деформаціях стиску в 17,4 рази більше, ніж при руйнуванні зсувними напруженнями.

При руйнуванні породи в кульових млинах присутнє розчавлювання i стирання шматків від кочення куль, зіткнення шарів завантаження між собою, виникають зсувні деформації в шматках в середині шару завантаження та на поверхні футеровки, удари від падіння шматків та куль. Від того, який спосіб буде переважаючим і який внесок кожного з них, залежить кількість енергії, що витрачається на появу одиниці нової поверхні, тобто ефективність подрібнення

Експериментальні дослідження [9] та аналітичні методи [7] розрахунку напруженого стану при великих незворотних деформаціях та залишкової міцності дозволили встановити, що 3 ростом бічного тиску ступінь подрібнення порід при деформації має межу. При зменшенні розміру, частинки дроблення після де-якого розміру практично перестають подрібнюватись. Це визначається розмірами структурних елементів: зерен і кристалів.

Таким чином, враховуючи вище наведене, а також конструктивні i технологічні особливості роботи трубчастих кульових млинів треба усвідомлювати, що результати їх ефективності подрібнювання та енергозаощадження залежать від безлічі факторів. Основними 3 них є: 
крупність вхідних шматків породи, розмір і розподіл кульок, швидкість обертання барабана, форма і матеріал футеровки, а також обсяг завантаження при сухому та вологому подрібнюванні.

В роботі реалізована ідея підвищення ефективності подрібнення за рахунок використання сили внутрішнього та контактного тертя частинок породи між собою, з металевими кульками та з футеровкою внутрішніх стінок барабану за принципом: руйнування гірської породи за рахунок створення переважно зсувних напружень.

Метою роботи $€$ пошук найбільш ефективного співвідношення технологічних та конструктивних параметрів процесу дезінтеграції (подрібнення) рудних матеріалів у барабанному млині, на основі моделювання самого процесу руйнування матеріалу.

Для розрахунку напруженого стану та деформації породи в шарі приймемо слідуючи припущення: руйнування гірської породи відбувається коли значення зсувної складової напруженого стану досягає межі міцності; в якості граничного по зсувними напруженням значення використовується межа пружності, так як межі міцності і позамежної міцності мають у більшості видів гірських порід на порядок меншу зону (область) існування, а також високий коефіцієнт крихкості; для вивчення напруженого стану гірських порід в умовах нерівнокомпонентного стиснення використовуються дані про властивості гірських порід, отримані експериментально в умовах одновісного стиску, або аналітично по методикам [7].

Змоделюємо процес взаємодії шматків гірської породи в технологічному процесі подрібнення для аналізу ефективності та визначення рівня енерговитрат у вигляді потенційної енергії деформації породи в шарі. Моделювання плоского напруженого стану виконується на основі методу скінчених елементів (MKE) [8] з застосуванням пакета програм Solidworks.

Математичне моделювання побудовано на основі чисельного рішення МKE, де основні залежності напружено-деформованого стану елементів завантаження в барабанному млині представлені в опису типу скінченого елементу.

Скінчено-елементну модель напружено-деформованого стану завантаження млина будуємо за наступними етапами:

1. Формування геометрії моделі, що включає визначення геометричних місць характерних зон кульового млина, врахування хаотичного стану шматків руди з можливим падінням куль, руху шарів елементів завантаження.

2. Генерація сітки скінчених елементів, шматків руди, що деформуються, кульок, внутрішніх стінок футеровки млина.

3. Виділення граничних умов взаємодії елементів. 
4. Завдання властивостей матеріалів гірської породи, розмірів кульок, властивостей футеровки барабану млина.

5. Моделювання діючого навантаження на виділені елементи завантажень.

6. Графічна інтерпретація отриманих результатів по напруженню.

Аналіз великого числа експериментальних результатів [3, 5] показав, що в умовах об'ємного нерівнокомпонентного стиснення гірської породи руйнування відбувається за рахунок проростання критично орієнтованих зсувних тріщин.

На основі вище представленого аналізу можна підтвердити гіпотезу про наявність зсувного механізму руйнування матеріалу в млині, який підсилюється при вологому подрібненні (рис. 2) та при сухому - 3 неповним заповненням пустот між кулями, що відповідає моделі більш ефективного ковзного стиснення, який $\epsilon$ основним фактором ефективного процесу дезінтеграції [10] .

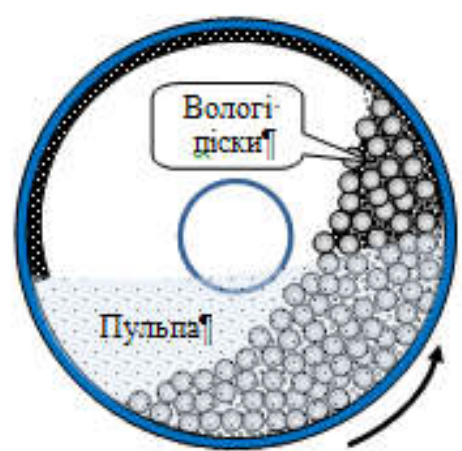

Рисунок 2 - Схема руху кульок та рудного матеріалу в трубчастому млині при вологому подрібненні

На користь прийнятого твердження свідчить i встановлений експериментально та аналітично механізм самоорганізації руйнування та розвитку деформації за межею міцності [7] по площинах зсуву, які формуються на майданчиках контакту [3].

При побудові моделі враховувалися особливості навантаження шматків руди в барабанному млині.

При сухому подрібненні в режимі неповного заповнення породою стінки барабана захоплюють вгору кулі, а кулі, в свою чергу захоплюють частинки породи. При скочуванні навантаження по похилому схилу частинки породи не скочуються разом з кулями, а прагнуть провалитися в порожнечі між ними вертикально вниз. Це призводить до зсувного стискання, а отже до виникнення зсувних деформацій.

При вологому подрібненні енергія руху куль більш ефективно використовується у верхній, збезводненій зоні, в якій є можливість руйнування 
декількох частинок, а не однієї, як у пульпі. Це призводить до більш ефективного руйнування за рахунок збільшення зсувних деформацій [10].

Також при використанні хвилястого профілю футерування виникає бічний тиск, в зв'язку з цим існує можливість зсуву зерен один відносно одного через неоднорідність по крупності всього шару матеріалу. Тому при оцінці опору гірської породи руйнуванню найбільш доцільно прийняти концепцію оцінки їі міцності за максимальними зсувними напруженнями.

Дані різних досліджень $[4,6]$ показують, що в зсувному потоці можуть існувати три основні механізми появи напружень: контактного тертя між частинками, тертя між частинками та кульками та між частинками i футеровкою, перенесення імпульсу за рахунок переміщення елементів породи з одного шару в інший та перенесення імпульсу за рахунок зіткнення між елементами. Всі ці механізми діють при русі елементів завантаження в камері барабанного млина. Хоча вони діють одночасно, особливості роботи барабанного млина дозволяють виділити області руху елементів завантаження, де переважає один з видів напруження.

Розглянемо процес передачі імпульсу углиб елементів завантаження. Представимо елементи завантаження, розташовані в площині перетину, у вигляді похилого ланцюжка, які рухаються разом 3 іншою частиною завантаження, піддаються тиску від опору сусідніх елементів. 3 певним ступенем точності такі напруження можна вважати плоскими.

Внутрішній об'єм барабанного млина із завантаженням розбивається на плоскі поперечні перерізи які, в свою чергу, складаються з шарів елементарних елементів завантаження, що рухаються по траєкторіях. Вважаємо, що зазначені елементи завантаження, на які розбитий весь обсяг млина, мають однакову форму з ребром $\Delta l$.

Приймемо, що на тіло, яке знаходиться в стані рівноваги, діють зовнішні сили. Для нього задається деяке віртуальне поле переміщень, яке будемо шукати. Переміщення характеризується в кожній точці простору значенням вектору. Рівновага буде тільки тоді, коли при довільних варіаціях переміщень віртуальна робота зовнішніх сил дорівнює роботі внутрішніх сил опору деформованого тіла. При цьому поле віртуальних переміщень на континуумі деформованого тіла має бути представлено безперервними функціями просторових координат і задовольняти кінематичним умов на його кордонах.

За теорії пружності деформованого тіла відомо, що сума змін потенційної енергії зовнішніх навантажень і внутрішньої енергії деформації при деякому полі переміщень дорівнює нулю. Тобто, як і в роботі [6] маємо:

$$
d\left(\Lambda+W_{p}\right)=d(\Pi)=0 \text {. }
$$


Робота зовнішніх навантажень $W$ дорівнює потенційній енергії опору тіла, що деформується, тобто $W_{p}=-W$. Таким чином, енергетичний стан механічної системи, яка деформується характеризується виразом вигляду $\frac{\partial(\Pi)}{\partial\{\delta\}}=0$. Кожне 3 складових потенційної енергії деформування $\Pi \in$ деякою функцією від вектору переміщень $\{\delta\}$. Функціонал потенційної енергії для дискретної області визначення деформованого тіла запишемо у вигляді

$$
\Pi=\sum_{e=1}^{E}\left(\Lambda^{e}-W^{e}\right)=\sum_{e=1}^{E} \Pi^{e}
$$

де $E$ - число елементів дискретної області визначення; $\Pi^{(e)}$ - частка потенційної енергії окремого скінченого елемента. Тоді запишемо необхідні вирази для складових повної потенційної енергії тіла, що деформується на скінченому елементі. Внутрішня енергія деформації для моделювання середовища гірських порід визначається виразом вигляду:

$$
\Lambda^{e}=\int_{v^{e}} 1 / 2\left(\{\varepsilon\}^{T}\{\delta\}\right) d v
$$

де інтегрування ведеться за обсягом скінченого елемента $-V^{e}$.

Обчислення вектору напружень $\{\delta\}$ проводиться після рішення основної системи рівнянь, здійснюється за відомими вузловими значеннями поля переміщень і деформацій скінченого елемента. Для представлення результатів розрахунку досить обчислити напруження в вузлах і в центрі скінченого елемента. Вектор напруження в вузлі скінченого елемента записується у вигляді $\{\sigma\}=[D][B]\{\delta\}^{(e)}$, де $[B]-$ матриця деформацій.

Вирішення цього завдання перевірено на прикладі фрагмента шару, скінчено-елементна модель якого побудована із застосуванням об'ємного напружено-деформованого стану, де товщина фрагмента (в напрямку осі Z) дорівнює 1 мм.

При моделюванні плоско-навантаженого стану середовища, як і в роботі [6] виділимо три характерних положення елемента завантаження.

У першому випадку елементи завантаження в зоні п'яти знаходяться на гумовій футеровці під тиском верхніх куль навантаження і падіння кулі, діаметром 100мм зі швидкістю в момент удару - 0,4 м/с. Враховується, що діють переважно нормальні напруження. На рисунку 3 показані розрахункові напруження, які виникають в елементах завантаження на гумовій поверхні футеровки після удару їх кулями, які падають в районі п'яти. 


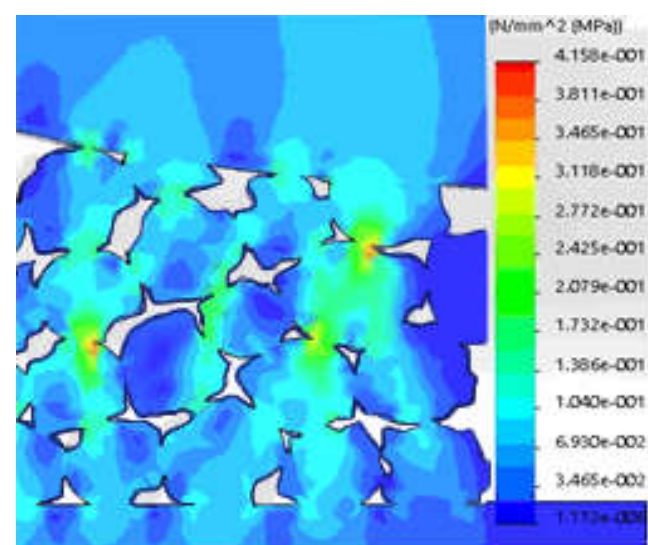

Рисунок 3 - Напруження в елементах частинок породи в момент падіння кульки

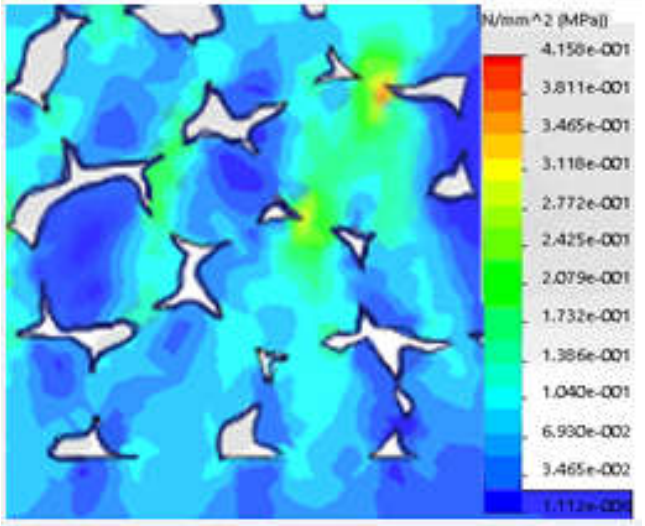

Рисунок 4 - Напруження в частинках породи в середині шару під тиском верхніх елементів завантаження

У другому випадку діє тиск тільки верхніх куль завантаження, який визначається насипною щільністю матеріалу породи і висотою шару. Для розрахунку прийнята щільність $\rho=5250 \mathrm{kг} / \mathrm{M}^{3}$, і висота шару - 1 м. В даному характерному випадку (рисунок 4) - розрахункове навантаження нижніх елементів (шматків) завантаження під тиском верхніх елементів завантаження заданої висоти шару і щільності елементів. При цьому нормальні напруження всередині елементів завантаження в області контакту з кульками слабшають, зате збільшуються навантаження з боку елементів шару.

У третьому випадку діє тиск, який сформований таким же чином, але вже під деяким кутом. Відбувається підйом елементів завантаження, і необхідно враховувати появу дотичних напружень i, відповідно, напружень зрушення. На рис. 5 показані напруження в частинках породи в результаті деформацій зсуву всередині завантаження в зоні підйому 3 позиції балансу енергетичних величин процесу подрібнення: роботи зовнішнього силового впливу і значення внутрішньої потенційної енергії деформації шматків руди та засноване на використанні методу скінчених елементів, аналізу напружено-деформованого стану елементів завантаження, обліку складної структури взаємодії шматків руди в шарі частинок під тиском.

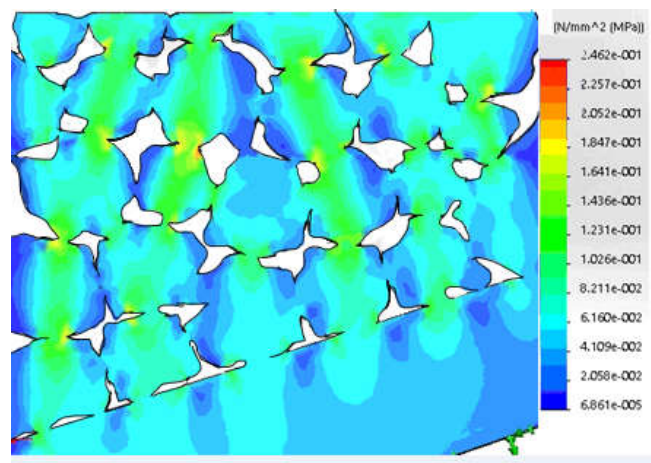

Рисунок 5 - Напружения в елементах завантаження при появі зсувних напружень на межі міцності матеріалу 
Виділений в будь-якому місці шматка породи елемент завантаження піддається деформації з боку сусідніх елементів (шматків породи або кульок) в умовах всебічного нерівнокомпонентного стиснення контактними силами. Данні сили визначають появу максимальних зсувних (дотичних) напружень, які залежать від максимальних нормальних напружень, що виникають на контактних майданчиках шматків породи. Для цього елемента побудовані епюри напружень.

На рисунку 6 показані епюри максимальних нормальних напружень, які виникають на вказаний елемент в трьох розрахункових положеннях.
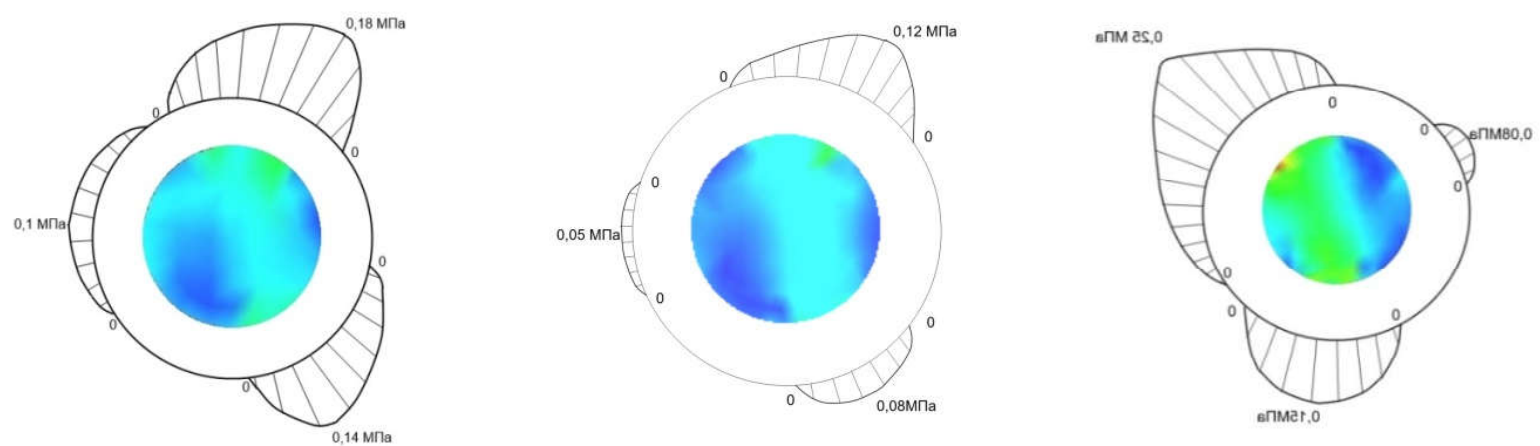

Рисунок 6 - Епюри нормальних напружень для наведених вище положень елементів завантаження

Розрахунки показали, що найбільші нормальні напруження в елементі в середині розрахункової області, знаходяться в третьому випадку. В різних дослідженнях та в роботі [11] показано, що при збільшенні $\sigma_{2}$ відбувається перехід напруженого стоану елемента породи 3 всебічного нерівнокомпонентного стиснення в область узагальненого зсуву i розтягування, об'ємна міцність порід різко зменшується.

Це підтверджує, що при використанні вологого подрібнення та сухого 3 неповним завантаженням [10] складаються більш сприятливі умови до зсувного стиснення частинок породи, що в свою чергу призводить до появи руйнівних дотичних напружень, які перевищують межу міцності за критерієм Кулона на лініях зсуву. Відбувається процес ефективного руйнування породи.

Таким чином, моделювання процесу руйнування породи в кульовому млині на основі дослідження напружень в шматках породи в шарі завантаження методом скінчених елементів на базі пакету Solidworks показало, що основним впливом на руйнування $є$ поява зсувних напружень в частинках породи.

Розроблена модель підтверджена отриманими експериментальними результатами дезінтеграції міцних залізних руд на ВАТ «Полтавський ГЗК» на 
мілину-Ницаха МШР-4,0*5,0 першої стадії подрібнення 3 кулями діаметром 100 мм. Це дозволило в технологічних схемах рудопідготовки з вхідним класом породи 6-8мм знизити питомі витрати кульок на 10\% і знизити питомі витрати електроенергії в цілому на технологічну секцію на 5-6\%.

\section{Висновки}

1. Розроблена математична модель процесу подрібнення рудних матеріалів в кульовому млині 3 позиції балансу енергетичних величин процесу руйнування: роботи зовнішнього силового впливу i значення внутрішньої потенційної енергії деформації шматків руди 3 використанням методу скінчених елементів, аналізу напруженодеформованого стану елементів завантаження, взаємодії шматків руди в шарі частинок під тиском за умови зміни зсувних i ударних навантажень. Математична модель дозволяє розрахувати максимальні навантаження в елементах завантаження (руда, кулі, вода).

2. Показано, що виділений в будь-якому місці елемент завантаження піддається деформації з боку сусідніх елементів завантаження (шматків руди) в умовах всебічного нерівнокомпонентного стиснення контактними силами. Данні сили визначають появу максимальних зсувних (дотичних) напружень, які залежать від максимальних нормальних напружень, що виникають в шматках породи.

3. Результати моделювання напружено-деформованого стану елементів завантаження підтвердили, що при застосуванні вологого подрібнення та сухого подрібнення з неповним завантаженням складаються більш сприятливі умови до зсувного стиснення частинок породи, що в свою чергу призводить до появи руйнівних дотичних напружень, які перевищують межу міцності за критерієм Кулона на лініях зсуву. Відбувається процес ефективного руйнування породи, що в свою чергу веде до зниження енергоємності процесу подрібнення.

\section{ЛIТЕРАТУРА}

1. Маляров П.В. Основы интенсификации процессов рудоподготовки / П.В. Маляров - Ростов на- Дону, 2004.- 185 с.

2. Андреев Е.Е. Дробление, измельчение и подготовка сырья к обогащению: Учебник / Е.Е. Андреев, О.Н. Тихонов - Санкт-Петербургский государственный горный институт (технический университет). СПБ.- 2007.- 439 с.

3. Блохин В.С., Большаков В.И., Малич Н.Г. Основные параметры технологических машин. Машины для дезинтеграции твердых материалов: Учебное пособие ч.1 - Днепропетровск; ИМА - пресс.- 2006. - 404c.

4. Науменко Ю.В. Основи теорії режимів роботи барабанних млинів: Монографія / Ю.В. Науменко. - Рівне: Вид-во СПД Зелент О.І., 2009.-282с. 
5. Дырда В.И. Кинетика измельчения минерального сырья в шаровых мельницах с резиновой футеровкой / В.И. Дырда, В.А. Калашников, И.В. Хмель, Е.В. Калганков // Геотехнічна механіка.- 2013. № 108.- с. 89 - 96.

6. Хмель И.В. Моделирование процесса дезинтеграции магнетитовых кварцитов в барабанной мельнице на основе использования метода конечных элементов / И. В. Хмель // Вісник Нац. техн. ун-ту "ХПІ": зб. наук. пр. Сер.: Механіко-технологічні системи та комплекси. - Харків: НТУ "ХПІ", 2016. - № 17 (1189). - С. 83-88.

7. Васильев Л.М., Васильев Д.Л., Малич Н.Г., Ангеловский А.А. Механика образования форм разрушения образцов горных пород: Монография.- Днипро, ИМА-пресс.-2018-172с.

8. Морозов Е.М. Метод конечных элементов в механике разрушения / Е.М. Морозов, Г.П. Никишков- М.: Наука, - 1980. - 254 с.

9. Олейник Т.А. Исследование влияния резиновых футеровочных плит на эффективность измельчения руды Северного ГОКа / Т.А. Олейник., И.В Хмель // Вісник КНУ- Вип. 34.Кривий Ріг.-2013.- С. 123-127.

10.Малич Н.Г., Усов О.А. Анализ характера напряженного состояния породы в процессах измельчения полезных ископаемых // Металлург. и горнорудн. пром-сть. - 2018. №7. - С. 51 - 56.

11.Деформирование и разрушение горных пород в условиях объемного неравнокомпонентного сжатия / В.Н. Ревва // Физико-технические проблемы горного производства: Сб. науч. тр. 2008. - Вип. 11. - С. 98-110.

\section{REFERENCES}

1. Malyarov P.V. Fundamentals of intensification of ore preparation processes / P.V. Malyarov Rostov - on - Don, 2004. - 185 p.

2. Andreev E.E. Crushing, grinding and preparation of raw materials for enrichment: Textbook / HER. Andreev, O. N. Tikhonov - Saint Petersburg State Mining Institute (Technical University). St. Petersburg - 2007. - 439 p.

3. Blokhin V.S., Bolshakov V.I., Malich N.G. The main parameters of technological machines. Machines for disintegration of solid materials: Study guide, part 1 - Dnepropetrovsk; IMA-press. 2006. - $404 \mathrm{p}$.

4. Naumenko Yu.V. Fundamentals of the theory of modes of operation of drum mills: Monograph / Yu.V. Naumenko. - Rivne: Publishing house SPD Zelent OI, 2009. - 282 p.

5. Dyrda V.I. Kinetics of grinding mineral raw materials in rubber-lined ball mills / V.I. Dyrda, V.A. Kalashnikov, I.V. Khmel, E.V. Kalgankov // Geotechnical mechanics.- 2013. No. 108.- p. 89 - 96.

6. Khmel I.V. Simulation of the disintegration process of magnetite quartzite in a drum mill based on the use of the finite element method / I. V. Khmel // Bulletin of the National Academy of Sciences. tech. un-tu "KhPI": zb. sciences. pr. Ser .: Mechanical and technological systems and complexes. Kharkiv: NTU "KhPI", 2016. - No. 17 (1189). - p. 83-88.

7. Vasiliev L.M., Vasiliev D.L., Malich N.G., Angelovsky A.A. Mechanics of Formation of Forms of Fracture of Rock Samples: Monograph. - Dnipro, IMA-press. -2018-172 p.

8. Morozov E.M. Finite element method in fracture mechanics / E.M. Morozov, G.P. Nikishkov - M .: Nauka, - 1980. - 254 p.

9. Oleinik T.A. Study of the Influence of Rubber Lining Plates on the Efficiency of Ore Grinding of Severny GOK / T.A. Oleynik., I.V. Khmel // Bulletin of KNU-Vip. 34.-Curve Rig.-2013. - p. 123-127.

10. Malich N.G., Usov O.A. Analysis of the nature of the stress state of the rock in the processes of grinding minerals // Metallurg. and mining prom-st. - 2018. - No. 7. - p. 51 - 56.

11.Deformation and destruction of rocks in conditions of volumetric unequal-component compression / V.N. Revva // Physical and technical problems of mining: Sat. scientific. tr. - 2008. VIP. 11. - p. 98-110. 
UDC 39.311-06-05

M. Malich

\section{MODELING OF THE PROCESS OF DISAGGREGATION OF ORE ROCK IN A DRUM MILL USING THE FINISHED ELEMENT METHOD}

Peculiarities of ore materials movement in a drum mill are considered. A mathematical model of ore materials grinding process in a drum ball mill is developed from the position of balance of energy quantities of destruction process: work of external force influence and value of internal potential energy of deformation of ore pieces. Using the finite element method, the analysis of the stress-strain state of the loading elements, the interaction of pieces of ore in the layer of particles under pressure under the condition of changes in shear and shock loads. The mathematical model allows to calculate the maximum loads in the loading elements (ore, spheres).

It is shown that the loading element selected anywhere is subject to deformation by the neighboring loading elements (pieces of ore) under conditions of comprehensive nonuniform component compression by contact forces. These forces determine the appearance of maximum shear (tangential) stresses, which depend on the maximum normal stresses occurring in the pieces of rock.

The results of modeling the stress-strain state of the loading elements confirmed that the use of wet grinding and dry grinding with incomplete loading creates more favorable conditions for shear compression of rock particles, which in turn leads to destructive tangential stresses exceeding the Coulomb strength. shear lines. There is a process of effective destruction of the rock, which in turn leads to a decrease in the energy consumption of the grinding process.

Keywords: ore mass, tube ball mill, contact grinding friction, fracture, stress, modeling.

Маліч Микола Григорович - к.т.н., доцент, Національна металургійна академія України, Україна.

Малич Николай Григорьевич - к.т.н., доцент, Национальная металлургическая академия Украины, Украина.

Malich Mykola - Candidate of Technical Sciences, Associate Professor, The National Metallurgical Academy of Ukraine. 